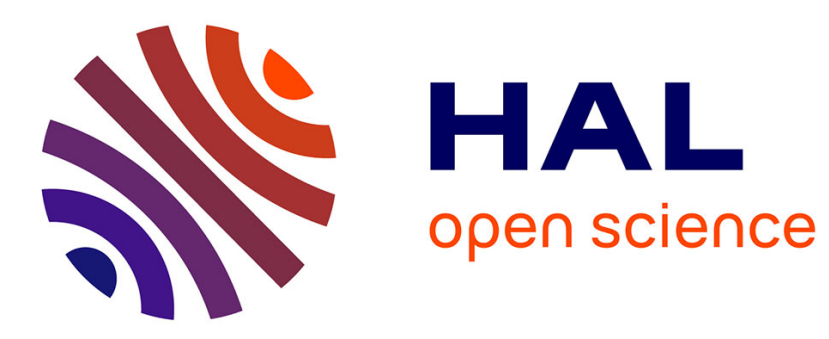

\title{
The role of family history in mental health service utilization for major depression.
}

Elena Prokofyeva, Silvia S. Martins, Nadia Younès, Pamela J. Surkan, Maria

Melchior

\section{- To cite this version:}

Elena Prokofyeva, Silvia S. Martins, Nadia Younès, Pamela J. Surkan, Maria Melchior. The role of family history in mental health service utilization for major depression.. Journal of Affective Disorders, 2013, 151 (2), pp.461-6. 10.1016/j.jad.2013.06.025 . inserm-00848341

\section{HAL Id: inserm-00848341 https://www.hal.inserm.fr/inserm-00848341}

Submitted on 26 Jul 2013

HAL is a multi-disciplinary open access archive for the deposit and dissemination of scientific research documents, whether they are published or not. The documents may come from teaching and research institutions in France or abroad, or from public or private research centers.
L'archive ouverte pluridisciplinaire HAL, est destinée au dépôt et à la diffusion de documents scientifiques de niveau recherche, publiés ou non, émanant des établissements d'enseignement et de recherche français ou étrangers, des laboratoires publics ou privés. 
The role of family history in mental health service utilization for major depression.

Elena Prokofyeva M.D., M.P.H., Ph.D. ${ }^{1,2}$, Silvia S. Martins M.D., Ph.D. ${ }^{3}$, Nadia Younès M.D., Ph.D. ${ }^{4}$, Pamela J. Surkan Sc.D. ${ }^{5}$, Maria Melchior Sc.D. ${ }^{1,2}$

1. Inserm, U1018, Centre for Research in Epidemiology \& Population Health (CESP), Epidemiology of occupational and social determinants of health, F-94807, Villejuif, France

2. University of Versailles Saint-Quentin, UMRS 1018, F-94807, Villejuif, France

3. Department of Epidemiology, Columbia University, Mailman School of Public Health, New York, NY 10032.

4. Université de Versailles Saint-Quentin EA 4047, Centre Hospitalier de Versailles, Le Chesnay, France

5. Department of International Health, Johns Hopkins Bloomberg School of Public Health, Baltimore, MD, USA

Corresponding author: Dr. Elena Prokofyeva, Inserm U1018, Equipe 11, Hôpital Paul-Brousse, Bâtiment 15, 16 avenue Paul Vaillant Couturier, 94807 VILLEJUIF CEDEX France, elena.prokofyeva@inserm.fr, Tel. +33(0)177747413, Fax:+33 (0)1 77747403. 


\begin{abstract}
Background: The purpose of the study was to examine the association between family history of major depressive disorder (MDD) and mental health service utilization for MDD.

Methods: Data come from wave 1 (2001-2) and wave 2 (2004-5) of the US National Epidemiologic Survey on Alcohol and Related Conditions (NESARC). The AUDADIS was used to determine the presence of lifetime and incident MDD. Participants with a mother, father, grandparent or sibling with MDD were considered to have a positive family history. Mental health service utilization among participants with lifetime MDD was studied. Data were analyzed using logistic regression models adjusted for socio-demographic characteristics (age, sex, education, marital status, family income) and disease severity.

Results: 7,940 NESARC participants had lifetime MDD, 54.7\% of them had family history of the disorder. Compared to participants with no family history of MDD, those with such family history were two times more likely to access treatment (OR: 2.37, 95\% CI: 2.11-2.68). Parental, and particularly maternal history of MDD, was most strongly associated with MDD treatment.
\end{abstract}

Limitations: Data were unavailable on the timing of family history of MDD and its possible under-report, and differences between participants with treated vs untreated relatives. Institutionalized individuals were not included.

Conclusions: Individuals with parental and maternal history of major depression were two times more likely to receive treatment for MDD than those with no such history. Efforts to increase access to healthcare for those who do not report family history of MDD could prove effective in addressing existing unmet treatment needs. 
Keywords: family history, parental history, maternal history, paternal history, siblings' history, grandparents' history, major depression disorder, mental health service utilization 


\section{Introduction:}

Major depressive disorder (MDD) is common and disabling. Worldwide, 5-7\% of adults are affected at some point in time (Ferrari et al., 2012) and up to 25\% during their lifetime (Hasin et al., 2005). What is more, it is estimated that the number of adults with MDD will increase by $35 \%$ between 2005 and 2050, from 33.9 million to 45.8 million (Heo et al., 2008).

Access to adequate treatment can decrease the level of symptoms as well as the degree of impairment and economic burden associated with depression (Hasin et al., 2005; Luppa et al., 2007). Yet, not all depressed individuals receive treatment. Documented rates of mental health service utilization vary from $30 \%$ in the European ESEMeD study (Sevilla-Dedieu et al., 2011) to 55\% in the US-based NESARC (Hasin et al., 2005).

The familial nature of MDD has been well documented, which reflects both genetic as well as environmental influences (Avenevoli and Merikangas, 2006; Husain et al., 2009; Kendler et al., 1997; Klein et al., 2001; Lieb et al., 2002; McLaughlin et al., 2012a; Verhagen et al., 2008; Weissman et al., 2006b). Children of individuals who are depressed are three to four times more likely to experience a major depressive episode compared to those without such family history (Sullivan et al., 2000), particularly when the affected family member is the mother (Olfson et al., 2003; Scott et al., 2012; Weissman et al., 2006a). Familial depression has also been shown to predict earlier onset as well as greater depression severity (McLaughlin et al., 2012b; Sullivan et al., 2000), leading general practitioners to often use family history to screen for major depression, confirm a diagnosis, or make treatment decisions (Nierenberg et al., 2007).

To date, few studies have examined whether the relationship between family history of depression and mental health service utilization in case of a major depressive episode 
varies depending on which and how many family members are affected. Our study, based upon the National Epidemiologic Survey on Alcohol and Related Conditions (NESARC), a nationally representative study of the US population, examines the association between family history of major depression and mental health service utilization in case of lifetime or incident MDD, adjusting for sex, age, educational level, family income, marital status, ethnicity, and disease severity, which are known risk factors of depression. In particular, we examine whether the likelihood of treatment varies depending on the type of family history of MDD and the accumulation of familial risk. 


\section{Materials and Methods:}

Sample and Procedures: Data come from Wave 1 (2001-2) and Wave 2 (2004-5) of the National Epidemiologic Survey on Alcohol and Related Conditions (NESARC). This nationally representative study of the US population was conducted among noninstitutionalized adults ( $\geq 18$ years of age) residing in households and group quarters. AfricanAmericans, Hispanics, and individuals aged 18-24 years were oversampled. All participants were interviewed at home by experienced lay interviewers who received extensive training and supervision. All procedures, including informed consent, received full ethical review and approval from the U.S. Census Bureau and U.S. Office of Management and Budget. Of the 43,093 Wave 1 respondents, 34,653 were re-interviewed at wave 2. Excluding ineligible (e.g., deceased) respondents, the overall wave 2 response rate was $86.7 \%$. For the purpose of this analysis we merged study waves 1 and 2.

Major depressive disorder: MDD was ascertained using the AUDADIS, a structured interview designed to measure psychiatric disorders and associated conditions in large scale surveys, which follows DSM-IV criteria (American Psychiatric Association, 1994; Harris and Edlund, 2005). We studied both lifetime MDD (as assessed at waves 1 and 2 of the NESARC) and incident MDD (defined as MDD at wave 2 in participants who were previously never depressed). We evaluated the severity of MDD by the number of symptoms present.

Family history of depression: Data on family history of depression (mother, father, sibling, and grandparent) were obtained at wave 1 of the NESARC study. Family history of MDD was assessed in two steps. First, the investigator read to the participant descriptions of observable manifestations of MDD (Heiman et al., 2008) designed to collect family history information in a sensitive manner (Andreasen et al., 1977; Zimmerman et al., 1988). Second, 
participants were asked about family history of psychiatric disorders in different categories of relatives (mother, father, sibling, and grandparent). Family history was considered to be positive if a respondent had at least one relative (parent, sibling, or grandparent) ever diagnosed with or treated for major depression. Among participants with lifetime MDD, $53.9 \%$ reported having an affected sibling, $19.6 \%$ - an affected mother, $14.2 \%$ - an affected father, and $12.3 \%$ - an affected grandparent. The likelihood of depression in different family members was moderately correlated (correlation coefficients ranging from .29 - father and a sibling to .38 - a grandparent and a sibling).

Mental health treatment: Treatment receipt was ascertained in waves 1 and 2 in all NESARC participants who met criteria for MDD using the following questions: "Did you ever go to any kind of counselor, therapist, doctor, psychologist or any person like that to help improve your mood or make you feel better?" (outpatient treatment) or "Were you a patient in a hospital for at least one night because you felt sad, blue, depressed or down/didn't care about things or enjoy things?" (inpatient treatment) or "Did you ever go to an emergency room for help during any time when you felt sad, blue, depressed or down/ didn't care about things or enjoy things?" (emergency room) or "Did a doctor ever prescribe any medicines or drugs to improve your mood or to make you feel better?" (psychotropic drug therapy). These questions were combined and studied as a single variable measuring lifetime mental health service utilization for MDD.

Covariates: Similar to Andersen's model of health services utilization (Andersen, 1995), the regression model included predisposing factors: participants' sex (female vs. male), age (35$54, \geq 55$ years vs. 18-34 years); enabling factors : educational level ( $<$ high school vs. $\geq$ high school degree), marital status (not married vs. married), family income, dichotomized at the 
lowest quartile of the distribution (\$10,000-19000 vs. $\geq \$ 20,000 /$ year); and ethnicity (African American, Other non-Caucasian vs. Caucasian).

Statistical analysis: We restricted the study sample to participants who experienced lifetime $\operatorname{MDD}(\mathrm{n}=7,940,22.9 \%$ of the NESARC sample). First, we studied mental health service utilization in relation to overall family history of MDD. Second, we distinguished parental, maternal, paternal, sibling, and grandparent history of MDD. Third, we investigated mental health service utilization as a function of the number of family members who had a lifetime history of MDD. In additional analyses, we studied mental health service utilization among individuals with incident MDD $(\mathrm{n}=1,779)$.

Analyses were carried out in a logistic regression framework using STATA/SE 12; odds ratios and $95 \%$ confidence intervals were weighed to account for the complex sampling design. 


\section{Results:}

In our sample of 7,940 individuals with lifetime MDD, the mean age was 45.9 years $(\mathrm{SD}=15.5)$. As described in Table 1, participants with lifetime MDD were mostly female (65.4\%), aged 35-54 years (45.9\%), Caucasian (75.0\%), had graduated from high school $(86.4 \%)$, had a family income $\geq 20,000$ US dollars/year (75.8\%), and were married (55.9\%). Positive family history of MDD was reported in over half of the sample (54.7\%): $53.9 \%$ of participants had at least one sibling, $19.6 \%$ a mother, $14.2 \%$ a father, and $12.3 \%$ a grandparent with history of MDD. Most participants with lifetime MDD had two (46.4\%) or three $(21.6 \%)$ relatives with major depression. Participants with lifetime MDD differed from those with no lifetime MDD on all socio-demographic characteristics, except education level.

\section{Insert Table 1 here $\longrightarrow$}

\section{Lifetime mental health service utilization:}

The probability of being treated was highest in females, in participants who were older than 35 years of age, and who had higher education. It was lowest in participants who were not married and who were not White. As shown in Table 2, socio-demographic factors associated with treatment in case of MDD included female sex, age above 35 years, and higher level of education.

Insert Table 2 here

Family history of major depression and lifetime mental health service utilization:

$65.9 \%$ of participants who received treatment for MDD reported positive family history of the disorder; $56.5 \%$ reported positive parental history. As shown in Table 3, in bivariate analyses, all forms of family history of depression examined were significantly associated 
with mental health service utilization in case of MDD. Overall, participants with any family history of depression were over two times more likely to receive treatment. Examining the different specific types of family history, the ORs ranged from 1.64 when the affected relative was the father to 2.36 when the affected relative was the mother; the overall OR associated with parental history of depression was 2.47 (95\% CI: 2.19-2.77). After adjusting for socio-demographic factors, overall family history of depression remained the strongest predictor of treatment in case of MDD (multivariate OR 2.37, 95\% CI: 2.11-2.68). After additional adjustment for the number of symptoms of MDD, the magnitude of the association between treatment and family history of depression decreased but remained elevated and statistically significant (OR: 1.59, 95\% CI: 1.38-1.83).

Additionally, the likelihood of treatment was associated with the number of family members who had had depression (bivariate OR for each additional family member: 1.21, 95\% CI: 1.16-1.26). After adjusting for socio-demographic covariates, the association decreased but remained statistically significant (multivariate OR for each additional family member: $1.06,95 \%$ CI: $1.01-1.11)$.

\section{Insert Table 3}

In additional analyses, family history of depression was associated with treatment of the incident MDD (bivariate OR: 1.35, 95\% CI 1.5-1.74), but this association lost statistical significance after adjustment for covariates (multivariate OR: 1.20, 95\% CI: 0.92-1.55). We found no interactions between family history of depression and participant sex. 
Family history of major depression and type of mental health treatment:

$48.5 \%$ of participants with lifetime MDD received mental health treatment. As reported in Table 4 compared to participants with no family history of depression, those who did have such family history were significantly more likely to receive outpatient treatment $(12.2 \%$ vs. 9.6\%, p-value $<0.001$; adjusted OR: $2.06,95 \%$ CI: $1.67-2.53)$ or psychotropic medications (43.7\% vs. $25.6 \%$, p-value $<0.001$; adjusted OR: 2.59 , 95\% CI: $2.28-2.94)$. These associations decreased but remained elevated and statistically significant after we controlled for the number of depressive symptoms, (OR of outpatient treatment: 1.35, 95\% CI: 1.08-1.69; OR of psychotropic medications: OR: 1.60, 95\% CI: 1.37-1.87).

Similarly, those participants with maternal history of depression were more likely to receive outpatient treatment $(62.8 \%$ vs. $56.1 \%$, p-value $=0.0018)$ and psychotropic medications $(53.6 \%$ vs. $46.3 \%$, p-value $<0.001)$ than those with parental history of depression.

Insert Table 4 here $\longrightarrow$ 


\section{Discussion:}

Our study, based on a nationally representative sample of the US adult population suggests that among individuals with MDD a positive family history of major depression predicts an over two-fold probability of mental health service utilization, even after accounting for socio-demographic characteristics. Positive parental, and particularly maternal, history of major depression as well as the number of affected relatives is especially associated with a higher probability of treatment. Family history appears most strongly associated with outpatient and psychotropic medication treatment. Individuals with MDD and a positive maternal history of depression are more likely to receive outpatient and psychotropic medication treatment than those with a positive parental family history of MDD.

Prior to interpreting our findings, we need to acknowledge several limitations. First, MDD and treatment receipt for MDD were studied over participants' lifetimes, hence we have no information regarding the timing of family history in relation to participants' mental health. Nonetheless, because most cases of MDD occur prior to age 30 (Charlton et al., 2013; Kessler et al., 2007; Zisook et al., 2007) and because mental health service utilization was most strongly associated with parental history of depression, the impact of this bias is probably minor. Second, family history of MDD in the NESARC was assessed with a single question for each category of relatives, which could limit the reliability of this measure. However, since participants were presented with descriptions of manifestations of MDD and information from multiple family members, including parents and siblings, was used, the degree of misclassification is likely to be minor (Fenton et al., 2010; Heiman et al., 2008). Third, although often used in research and clinical settings, information on family history obtained from probands may have insufficient specificity (Duggan et al., 1998a; Kendler and 
Roy, 1995). Participants' reports typically underestimate family history of mental disorders, but this effect seems weaker in parents than in other, more remote, family members (Verweij et al., 2011). Fourth, data on family history of major depression is based on relatives ever being depressed (diagnosed or treated for depression). Participants with family members who were diagnosed and treated for depression could differ in terms of mental health services utilization for MDD from those whose relatives were diagnosed, but untreated. Fifth, our study population did not include individuals who were institutionalized and who may have elevated rates of major depression (Anckarsater et al., 2007). Overall, these methodological drawbacks are probably minor but may have led us to underestimate the strength of the association between family history of major depression and mental health service utilization. Our study also has strengths. First, we studied a nationally representative sample of the US adult population that limits selection bias. Second, major depression was ascertained using a structured diagnostic interview, evaluating the presence of clinically relevant disorders as measured by DSM-IV criteria (American Psychiatric Association, 1994). Third, we systematically investigated associations between different aspects of family history of major depression and MDD treatment.

Family history of major depression and mental health service utilization

In line with previous studies, fewer than half of study participants with MDD received treatment, stressing a high level of unmet need for treatment among people who are depressed (Hasin et al., 2005). Prevalence rates of family history of major depression in our study $(54.7 \%$ overall and $65.9 \%$ of those who received treatment for depression) are consistent with prior research (Duggan et al., 1998b; Nierenberg et al., 2007). One of the main findings of our study is that we showed the association between parental history of depression and the number of affected relatives as key familial predictors of mental health 
service utilization in case of MDD, particularly with regard to outpatient treatment and psychotropic drug therapy.

Several mechanisms can account for our findings. First, individuals with MDD may be more likely to report parental history of the same disorder because they are more sensitized to it (Chapman et al., 1994; Kendler et al., 1991). Reassuringly, family history data in our study were obtained from participants who have a central position in the family pedigree and can provide reliable information on their siblings and parents (Verweij et al., 2011). Second, family history of depression is a marker of greater severity (greater number of symptoms and comorbidities) and earlier disease onset (Keyes et al., 2012; McLaughlin et al., 2012a; Serretti et al., 2013), which also predicts treatment-seeking (Olfson et al., 2003). Nonetheless, we found that family history of depression is significantly associated with outpatient and psychotropic drug treatment rather than inpatient and emergency treatment, and that these associations holds even after controlling for the number of symptoms, suggesting that disorder severity is not the only explanation. Third, family history of depression was partly defined based on history of depression treatment and we believe that having a family member who was treated for depression may lead to higher awareness of depression symptoms and pathways for help seeking (Kendler, 1995; Nierenberg et al., 2007; Sullivan et al., 1996). Additionally, we found that the number of relatives with a history of major depression was also related to mental health service utilization for depression. This may partly reflect a stronger genetic and environmental predisposition to major depression which could translate to especially severe or persistent symptoms and result in treatmentseeking (McLaughlin et al., 2012a; Nierenberg et al., 2007). This could also be explained by a "family mental health literacy" which has not been yet studied at the family level to our knowledge. 
Among indicators of family history, maternal history of major depression appeared most strongly associated with treatment for MDD, in particular with outpatient and psychotropic drug therapy. In general, offspring tend to spend more time with mothers, who are often more open to express their depressive feelings in comparison to men, that can lead to higher awareness of maternal depression in comparison to paternal. Compared to men, women have higher rates of depression (Kessler, 2003), depression treatment (Nierenberg et al., 2007; Wang et al., 2005), and mental health literacy (Deen and Bridges, 2011; Kaneko and Motohashi, 2007; Swami, 2012), which could explain higher awareness of depression, mental health literacy and help seeking attitudes among the offspring. The study underlines a high level of unmet need for treatment among people who are depressed in the United States. Our findings suggested that among individuals with MDD, family history of the same disorder is associated with a two-fold increase in the likelihood of receiving disorder specific treatment, in particular, outpatient and psychotropic medications treatment. Positive parental, and particularly maternal, history of major depression as well as the number of affected relatives is associated with a higher probability of access for treatment for MDD. Participants with maternal history of depression were more likely to receive outpatient and psychotropic medication therapy in comparison to those with paternal history. Our results imply that individuals who received treatment for depression are not representative of all individuals who have the disorder, suggesting that general population studies are essential in understanding factors associated with depression trajectories. From a clinical standpoint, our study highlights the importance of general population initiatives that provide information about symptoms of MDD and treatment opportunities. Although more research is needed, our findings stress the importance of providing better access to treatment for those who are not aware or have no family history of MDD. 


\section{References:}

American Psychiatric Association (Ed.), 1994. Diagnostic and Statistical Manual of Mental Disorders. American Psychiatric Press, Washington, DC.

Anckarsater, H., Nilsson, T., Stahlberg, O., Gustafson, M., Saury, J.M., Rastam, M., Gillberg, C., 2007. Prevalences and configurations of mental disorders among institutionalized adolescents. Dev Neurorehabil 10, 57-65.

Andersen, R.M., 1995. Revisiting the behavioral model and access to medical care: does it matter? J Health Soc Behav 36, 1-10.

Andreasen, N.C., Endicott, J., Spitzer, R.L., Winokur, G., 1977. The family history method using diagnostic criteria. Reliability and validity. Arch Gen Psychiatry 34, 1229-1235.

Avenevoli, S., Merikangas, K.R., 2006. Implications of high-risk family studies for prevention of depression. Am J Prev Med 31, S126-135.

Chapman, T.F., Mannuzza, S., Klein, D.F., Fyer, A.J., 1994. Effects of informant mental disorder on psychiatric family history data. Am J Psychiatry 151, 574-579.

Charlton, R.A., Lamar, M., Ajilore, O., Kumar, A., 2013. Preliminary analysis of age of illness onset effects on symptom profiles in major depressive disorder. Int J Geriatr Psychiatry.

Deen, T.L., Bridges, A.J., 2011. Depression literacy: rates and relation to perceived need and mental health service utilization in a rural American sample. Rural Remote Health 11, 1803.

Duggan, C., Sham, P., Minne, C., Lee, A., Murray, R., 1998a. Does the method of data collection affect the reporting of depression in the relatives of depressed probands? J Affect Disord 47, 151-158.

Duggan, C., Sham, P., Minne, C., Lee, A., Murray, R., 1998b. Family history as a predictor of poor long-term outcome in depression. Br J Psychiatry 173, 527-530.

Fenton, M.C., Keyes, K.M., Martins, S.S., Hasin, D.S., 2010. The role of a prescription in anxiety medication use, abuse, and dependence. Am J Psychiatry 167, 1247-1253.

Ferrari, A.J., Somerville, A.J., Baxter, A.J., Norman, R., Patten, S.B., Vos, T., Whiteford, H.A., 2012. Global variation in the prevalence and incidence of major depressive disorder: a systematic review of the epidemiological literature. Psychol Med, 1-11. 
Harris, K.M., Edlund, M.J., 2005. Use of mental health care and substance abuse treatment among adults with co-occurring disorders. Psychiatric services 56, 954-959.

Hasin, D.S., Goodwin, R.D., Stinson, F.S., Grant, B.F., 2005. Epidemiology of major depressive disorder: results from the National Epidemiologic Survey on Alcoholism and Related Conditions. Arch Gen Psychiatry 62, 1097-1106.

Heiman, G.A., Ogburn, E., Gorroochurn, P., Keyes, K.M., Hasin, D., 2008. Evidence for a two-stage model of dependence using the NESARC and its implications for genetic association studies. Drug Alcohol Depend 92, 258-266.

Heo, M., Murphy, C.F., Fontaine, K.R., Bruce, M.L., Alexopoulos, G.S., 2008. Population projection of US adults with lifetime experience of depressive disorder by age and sex from year 2005 to 2050 . Int J Geriatr Psychiatry 23, 1266-1270.

Husain, M.M., Rush, A.J., Wisniewski, S.R., McClintock, S.M., Fava, M., Nierenberg, A.A., Davis, L., Balasubramani, G.K., Young, E., Albala, A.A., Trivedi, M.H., 2009. Family history of depression and therapeutic outcome: findings from STAR*D. J Clin Psychiatry 70, 185-195.

Kaneko, Y., Motohashi, Y., 2007. Male gender and low education with poor mental health literacy: a population-based study. J Epidemiol 17, 114-119.

Kendler, K.S., 1995. Is seeking treatment for depression predicted by a history of depression in relatives? Implications for family studies of affective disorder. Psychol Med 25, 807-814.

Kendler, K.S., Davis, C.G., Kessler, R.C., 1997. The familial aggregation of common psychiatric and substance use disorders in the National Comorbidity Survey: a family history study. Br J Psychiatry $170,541-548$.

Kendler, K.S., Roy, M.A., 1995. Validity of a diagnosis of lifetime major depression obtained by personal interview versus family history. Am J Psychiatry 152, 1608-1614.

Kendler, K.S., Silberg, J.L., Neale, M.C., Kessler, R.C., Heath, A.C., Eaves, L.J., 1991. The family history method: whose psychiatric history is measured? Am J Psychiatry 148, 1501-1504.

Kessler, R.C., 2003. Epidemiology of women and depression. J Affect Disord 74, 5-13. 
Kessler, R.C., Angermeyer, M., Anthony, J.C., R, D.E.G., Demyttenaere, K., Gasquet, I., G, D.E.G., Gluzman, S., Gureje, O., Haro, J.M., Kawakami, N., Karam, A., Levinson, D., Medina Mora, M.E., Oakley Browne, M.A., Posada-Villa, J., Stein, D.J., Adley Tsang, C.H., Aguilar-Gaxiola, S., Alonso, J., Lee, S., Heeringa, S., Pennell, B.E., Berglund, P., Gruber, M.J., Petukhova, M., Chatterji, S., Ustun, T.B., 2007. Lifetime prevalence and age-of-onset distributions of mental disorders in the World Health Organization's World Mental Health Survey Initiative. World Psychiatry 6, 168-176.

Keyes, K.M., Eaton, N.R., Krueger, R.F., McLaughlin, K.A., Wall, M.M., Grant, B.F., Hasin, D.S., 2012. Childhood maltreatment and the structure of common psychiatric disorders. Br J Psychiatry 200, 107-115.

Klein, D.N., Lewinsohn, P.M., Seeley, J.R., Rohde, P., 2001. A family study of major depressive disorder in a community sample of adolescents. Arch Gen Psychiatry 58, 13-20.

Lieb, R., Isensee, B., Hofler, M., Pfister, H., Wittchen, H.U., 2002. Parental major depression and the risk of depression and other mental disorders in offspring: a prospective-longitudinal community study. Arch Gen Psychiatry 59, 365-374.

Luppa, M., Heinrich, S., Angermeyer, M.C., Konig, H.H., Riedel-Heller, S.G., 2007. Cost-of-illness studies of depression: a systematic review. J Affect Disord 98, 29-43.

McLaughlin, K.A., Gadermann, A.M., Hwang, I., Sampson, N.A., Al-Hamzawi, A., Andrade, L.H., Angermeyer, M.C., Benjet, C., Bromet, E.J., Bruffaerts, R., Caldas-de-Almeida, J.M., de Girolamo, G., de Graaf, R., Florescu, S., Gureje, O., Haro, J.M., Hinkov, H.R., Horiguchi, I., Hu, C., Karam, A.N., Kovess-Masfety, V., Lee, S., Murphy, S.D., Nizamie, S.H., Posada-Villa, J., Williams, D.R., Kessler, R.C., 2012a. Parent psychopathology and offspring mental disorders: results from the WHO World Mental Health Surveys. The British journal of psychiatry: the journal of mental science 200, 290-299.

McLaughlin, K.A., Gadermann, A.M., Hwang, I., Sampson, N.A., Al-Hamzawi, A., Andrade, L.H., Angermeyer, M.C., Benjet, C., Bromet, E.J., Bruffaerts, R., Caldas-de-Almeida, J.M., de Girolamo, G., de Graaf, R., Florescu, S., Gureje, O., Haro, J.M., Hinkov, H.R., Horiguchi, I., Hu, C., Karam, A.N., Kovess-Masfety, V., Lee, S., Murphy, S.D., Nizamie, S.H., Posada-Villa, J., Williams, D.R., 
Kessler, R.C., 2012b. Parent psychopathology and offspring mental disorders: results from the WHO World Mental Health Surveys. Br J Psychiatry 200, 290-299.

Nierenberg, A.A., Trivedi, M.H., Fava, M., Biggs, M.M., Shores-Wilson, K., Wisniewski, S.R., Balasubramani, G.K., Rush, A.J., 2007. Family history of mood disorder and characteristics of major depressive disorder: a STAR*D (sequenced treatment alternatives to relieve depression) study. J Psychiatr Res 41, 214-221.

Olfson, M., Marcus, S.C., Druss, B., Alan Pincus, H., Weissman, M.M., 2003. Parental depression, child mental health problems, and health care utilization. Med Care 41, 716-721.

Scott, K.M., McLaughlin, K.A., Smith, D.A., Ellis, P.M., 2012. Childhood maltreatment and DSM-IV adult mental disorders: comparison of prospective and retrospective findings. The British journal of psychiatry: the journal of mental science $200,469-475$.

Serretti, A., Chiesa, A., Calati, R., Linotte, S., Sentissi, O., Papageorgiou, K., Kasper, S., Zohar, J., De Ronchi, D., Mendlewicz, J., Amital, D., Montgomery, S., Souery, D., 2013. Influence of family history of major depression, bipolar disorder, and suicide on clinical features in patients with major depression and bipolar disorder. Eur Arch Psychiatry Clin Neurosci 263, 93-103.

Sevilla-Dedieu, C., Kovess-Masfety, V., Angermeyer, M., Bruffaerts, R., Fernandez, A., De Girolamo, G., De Graaf, R., Haro, J.M., Konig, H.H., 2011. Measuring use of services for mental health problems in epidemiological surveys. Int J Methods Psychiatr Res 20, 182-191.

Sullivan, P.F., Neale, M.C., Kendler, K.S., 2000. Genetic epidemiology of major depression: review and meta-analysis. Am J Psychiatry 157, 1552-1562.

Sullivan, P.F., Wells, J.E., Joyce, P.R., Bushnell, J.A., Mulder, R.T., Oakley-Browne, M.A., 1996. Family history of depression in clinic and community samples. J Affect Disord 40, 159-168.

Swami, V., 2012. Mental health literacy of depression: gender differences and attitudinal antecedents in a representative British sample. PLoS One 7, e49779.

Verhagen, M., van der Meij, A., Franke, B., Vollebergh, W., de Graaf, R., Buitelaar, J., Janzing, J.G., 2008. Familiality of major depressive disorder and gender differences in comorbidity. Acta Psychiatr Scand 118, 130-138. 
Verweij, K.H., Derks, E.M., Hendriks, E.J., Cahn, W., 2011. The influence of informant characteristics on the reliability of family history interviews. Twin Res Hum Genet 14, 217-220.

Wang, P.S., Lane, M., Olfson, M., Pincus, H.A., Wells, K.B., Kessler, R.C., 2005. Twelve-month use of mental health services in the United States: results from the National Comorbidity Survey Replication. Arch Gen Psychiatry 62, 629-640.

Weissman, M.M., Pilowsky, D.J., Wickramaratne, P.J., Talati, A., Wisniewski, S.R., Fava, M., Hughes, C.W., Garber, J., Malloy, E., King, C.A., Cerda, G., Sood, A.B., Alpert, J.E., Trivedi, M.H., Rush, A.J., 2006a. Remissions in maternal depression and child psychopathology: a STAR*D-child report. Jama 295, 1389-1398.

Weissman, M.M., Wickramaratne, P., Nomura, Y., Warner, V., Pilowsky, D., Verdeli, H., 2006b. Offspring of depressed parents: 20 years later. Am J Psychiatry 163, 1001-1008.

Zimmerman, M., Coryell, W., Pfohl, B., Stangl, D., 1988. The reliability of the family history method for psychiatric diagnoses. Arch Gen Psychiatry 45, 320-322.

Zisook, S., Lesser, I., Stewart, J.W., Wisniewski, S.R., Balasubramani, G.K., Fava, M., Gilmer, W.S., Dresselhaus, T.R., Thase, M.E., Nierenberg, A.A., Trivedi, M.H., Rush, A.J., 2007. Effect of age at onset on the course of major depressive disorder. Am J Psychiatry 164, 1539-1546. 
Table 1. Socio-demographic characteristics and family history of major depression among study participants: NESARC, 2001/02-2004/05 (weighted \%, p-value).

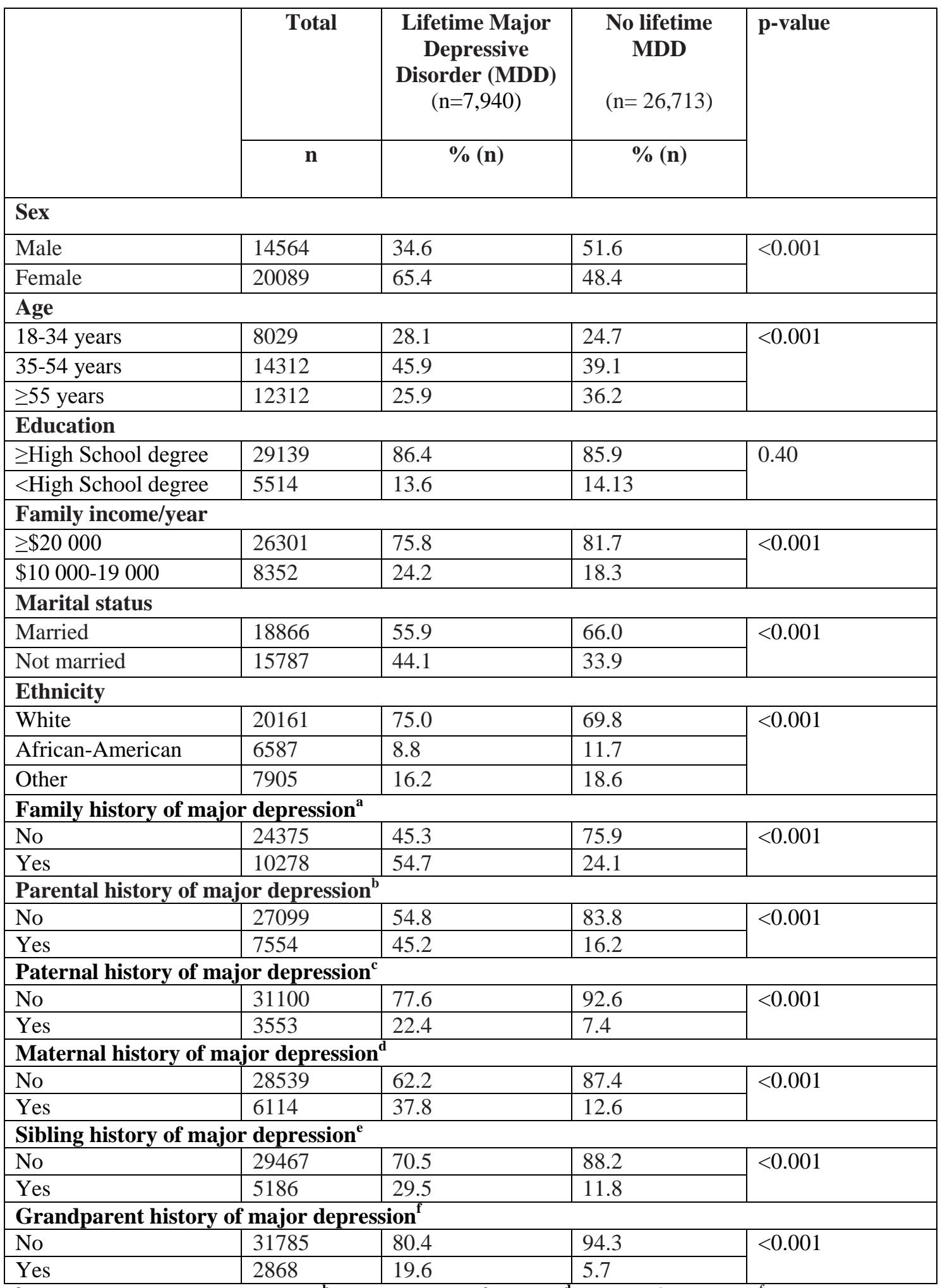

${ }^{\mathrm{a}}$ - parents, siblings, grandparents; ${ }^{\mathrm{b}}$ - father, mother; ${ }^{\mathrm{c}}$ - father; ${ }^{\mathrm{d}}$ - mother, ${ }^{\mathrm{e}}$ - siblings, ${ }^{\mathrm{f}}$ - grandparents. 
Table 2. Socio-demographic characteristics and treatment of major depression in the NESARC study (2001/02- 2004/05, n=7940): bivariate logistic regression analysis (weighted ORs, 95\% CI).

\begin{tabular}{|l|l|l|}
\hline \multicolumn{2}{|l|}{ Bivariate OR } & 95\% CI \\
\hline Sex & 1 & \\
\hline Male & 1.60 & $1.41-1.82$ \\
\hline Female & 1 & \\
\hline Age & \multicolumn{2}{|l|}{} \\
\hline 18-34 years & 1.56 & $1.37-1.78$ \\
\hline 35-54 years & 1.61 & $1.40-1.85$ \\
\hline$\geq 55$ years & \multicolumn{2}{|l|}{} \\
\hline Educational level & 1 & \\
\hline$>$ High school degree & 1.58 & $1.33-1.89$ \\
\hline$\leq$ High school degree & \multicolumn{2}{|l|}{} \\
\hline Family income/year & 1 & \\
\hline$\geq \$ 20000$ & 0.88 & $0.78-1.01$ \\
\hline \$10 000-19,000 & \multicolumn{2}{|l|}{} \\
\hline Marital status & 1 & \\
\hline Married & 0.85 & $0.77-0.94$ \\
\hline Not married & \multicolumn{2}{|l|}{} \\
\hline Ethnicity & 1 & \\
\hline White & 0.43 & $0.37-0.50$ \\
\hline African-American & 0.49 & $0.42-0.57$ \\
\hline Other &
\end{tabular}


Table 3. Family history of major depression and treatment of MDD in the NESARC study (2001/22004/5, n=7940): multivariate logistic regression analyses (weighted ORs, 95\% CI).

\begin{tabular}{|c|c|c|c|c|}
\hline & Bivariate OR & $95 \% \mathrm{CI}$ & $\begin{array}{l}\text { Multivariate } \\
\text { OR* }\end{array}$ & $95 \% \mathrm{CI}$ \\
\hline \multicolumn{5}{|c|}{ Family history of major depression ${ }^{a}$} \\
\hline No & 1 & & 1 & \\
\hline Yes & 2.44 & $2.18-2.72$ & 2.37 & $2.11-2.68$ \\
\hline \multicolumn{5}{|c|}{ Parental history of major depression ${ }^{b}$} \\
\hline No & 1 & & 1 & \\
\hline Yes & 2.47 & $2.19-2.77$ & 2.05 & $1.78-2.36$ \\
\hline \multicolumn{5}{|c|}{ Paternal history of major depression ${ }^{\mathrm{c}, 1}$} \\
\hline No & 1 & & 1 & \\
\hline Yes & 1.64 & $1.41-1.91$ & 1.11 & $0.94-1.31$ \\
\hline \multicolumn{5}{|c|}{ Maternal history of major depression $^{\mathrm{d}, \mathrm{I}}$} \\
\hline No & 1 & & 1 & \\
\hline Yes & 2.36 & $2.10-2.64$ & 1.92 & $1.67-2.21$ \\
\hline \multicolumn{5}{|c|}{ Grandparent history of major depression ${ }^{1}$} \\
\hline No & 1 & & 1 & \\
\hline Yes & 2.04 & $1.80-2.33$ & 1.41 & $1.21-1.66$ \\
\hline \multicolumn{5}{|c|}{ Sibling history of major depression ${ }^{\Gamma}$} \\
\hline No & 1 & & 1 & \\
\hline Yes & 1.81 & $1.61-2.03$ & 1.26 & $1.09-1.44$ \\
\hline $\begin{array}{l}\text { Number of family } \\
\text { relatives with history of } \\
\text { major depression }\end{array}$ & 1.21 & $1.16-1.26$ & 1.06 & $1.01-1.11$ \\
\hline
\end{tabular}

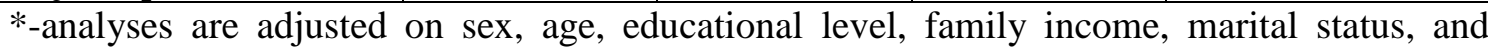
ethnicity.

a- parents, full siblings, grandparents; ${ }^{\mathbf{b}}$ - father, mother; ${ }^{\mathbf{c}}$ - father; ${ }^{\mathbf{d}}$ - mother

'-maternal and paternal, grandparents', and siblings' family histories of major depression were mutually adjusted. 
Table 4 Types of treatment for MDD in relation to family history of depression in the NESARC study $(2001 / 2-2004 / 5, n=7,940)$, weighted $\%$.

\begin{tabular}{|c|c|c|c|c|}
\hline Type of treatment & & $\begin{array}{l}\text { No family history } \\
\text { of depression } \\
(n=3,781)\end{array}$ & $\begin{array}{l}\text { Family history of } \\
\text { depression } \\
(\mathrm{n}=4,159)\end{array}$ & p-value \\
\hline \multirow[t]{2}{*}{ Any treatment } & No & $63.5 \%$ & $41.6 \%$ & \multirow[t]{2}{*}{$<0.001$} \\
\hline & Yes & $36.5 \%$ & $58.4 \%$ & \\
\hline \multirow{2}{*}{$\begin{array}{l}\text { Outpatient } \\
\text { treatment }\end{array}$} & No & $90.4 \%$ & $87.8 \%$ & \multirow[t]{2}{*}{0.005} \\
\hline & Yes & $9.6 \%$ & $12.2 \%$ & \\
\hline \multirow{2}{*}{$\begin{array}{l}\text { Inpatient } \\
\text { treatment }\end{array}$} & No & $99.5 \%$ & $99.6 \%$ & \multirow[t]{2}{*}{0.74} \\
\hline & Yes & $0.5 \%$ & $0.4 \%$ & \\
\hline \multirow[t]{2}{*}{ Emergency room } & No & $98.4 \%$ & $98.9 \%$ & \multirow[t]{2}{*}{0.18} \\
\hline & Yes & $1.6 \%$ & $1.1 \%$ & \\
\hline \multirow{2}{*}{$\begin{array}{l}\text { Psychotropic drug } \\
\text { therapy }\end{array}$} & No & $74.4 \%$ & $56.3 \%$ & \multirow[t]{2}{*}{$<0.001$} \\
\hline & Yes & $25.6 \%$ & $43.7 \%$ & \\
\hline
\end{tabular}


Acknowledgements: The National Epidemiologic Survey on Alcohol and Related Conditions (NESARC) is funded by the National Institute on Alcohol Abuse and Alcoholism (NIAAA) with supplemental support from the National Institute on Drug Abuse (NIDA). This research was supported by IReSP-the French Ministry of Health (2010 Research Call). Maria Melchior is the recipient of a Young Researcher Award from the French National Research Agency (ANR). 
Conflict of Interest: All other authors declare that they have no conflicts of interest. 
Role of the funding source: The funding sources for this study had no influence on the study design, the manner in which data were analysed, and interpreted, the writing of the report, or the decision to submit the paper for publication. 
Contributors: Dr. Elena Prokofyeva designed the study, wrote the protocol, undertook the literature searches, the statistical analysis, and wrote the first draft of the manuscript. Dr. Maria Melchior supervised the conception and design of the study, analyses, and interpretation of data. Dr. Silvia S. Martins, Dr. Nadia Younès, and Dr. Pamela J. Surkan made substantial contributions to the conception and design of the study, analysis and interpretation of data. All authors participated in revising the article critically for important intellectual content, read, and approved the final manuscript. 